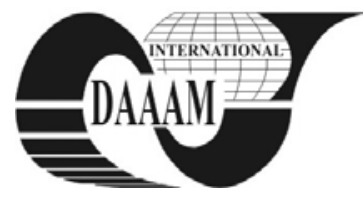

\title{
SAME ASPECTS REGARDING PRODUCTION MANAGEMENT IN SMALL AND MEDIUM INDUSTRIES UNDER EUROPEAN COMMUNITY INTEGRATION CONDITIONS
}

\author{
DUMITRESCU, C[onstantin] D[an]; TENT, I[onut] D[acian]; CORNU, G[eorgica]; \\ TRANDAFIR, N[icoleta] \& IRIMIE, S[abin] I[oan]
}

\begin{abstract}
This paper aim to make a pass between the world economy and the lean six sigma system and his contribution for the reduce cost for products and realize quality improvements and cost reduction potential by a logical and well-structured training approach. In the many company, starts to implement tis system in try to decrease production price.

Key words: lean six sigma, production system, world economy, quality
\end{abstract}

\section{INTRODUCTION}

After EU access to small and medium enterprises, by activity filed for accessing economic markets, have solved a particularly important and sensitiveat the same time: a positive response to the concept of economic solidarity and social partners that they come in contact. Globalization, economic and political power of transnational companies, powerful particulary emphasizes that economic interdependence has taken the place of absolute independence, creating interdependence both in political and social.

\section{TQM, LEAN SIX SIGMA AND INFLUENCE AT WORLD ECONOMY}

Global and regional economic structures are a direct result of interdependence, in Europe and worldwide, SMEs recommended strategy is to: quality of manufactured products and related services, quality equipment, quality manufacturing processes and know-how available, quality processes, marketing/detachament/sales and not least the quality of human resources available. Management methods applied to ensure the SME, the overall level of quality demanded by those who work with us, this means acquring a new vision on the concept of quality, but also the need for major long-term investment, conditions quite difficult to achieve for small and medium enterprises. In recent decades, the concepts of total quality management, six sigma, the large corporations have tried to be imposed direct employees through programs with varying degrees of complexity.

\section{WHAT IS THE LEAN SIX SIGMA?}

The concept of Six Sigma was launched by Motorola in 1987. It was the result of a series of changes in the quality area starting in the late 1970s, with ambitions ten - fold improvement drives. The top - level management along with CEO Robert Galvin developed a concept called Six Sigma. After some internal pilot implementations, Galvin, in 1987, formulated the goal of "achieving Six Sigma capability by 1992" in a memo to all Motorola employers (Bhote, 1989). The results in terms of reduction in process variation were on-track and cost savings totaled US\$ 13 billion and improvement in labor productivity achieved 204\% increase over the period 1987-1997(Losianowycz, 1999). In the wake of successes at Motorala, some leading electronic companies such as IBM, DEC and Texas Instruments launched Six Sigma programs in the early 90s. However, it was not until 1995 when GE and
Allied Signal launched Six Sigma as strategic initiatives that a rapid dissemination took place in non electronic industries all over the world. In early 1997, the Samsung and LG Groups in Korea began to introduce Six Sigma within their companies. The results were amazingly good in those companies. For instance, Samsung SDI, which is a company under the Samsung Group, reported that the cost savings by Six Sigma project totaled US\$ 150 millon. At a present time, the number of large companies applying Six Sigma is growing exponentially, with a strong vertical deployment intro many small and medium size enterprises as well. The Six Sigma concept is extremely powerful in improving the quality and speed of all types of "transactional" processes, including sales and marketing.

\section{BASIC ON CONCEP THE LEAN SIX SIGMA}

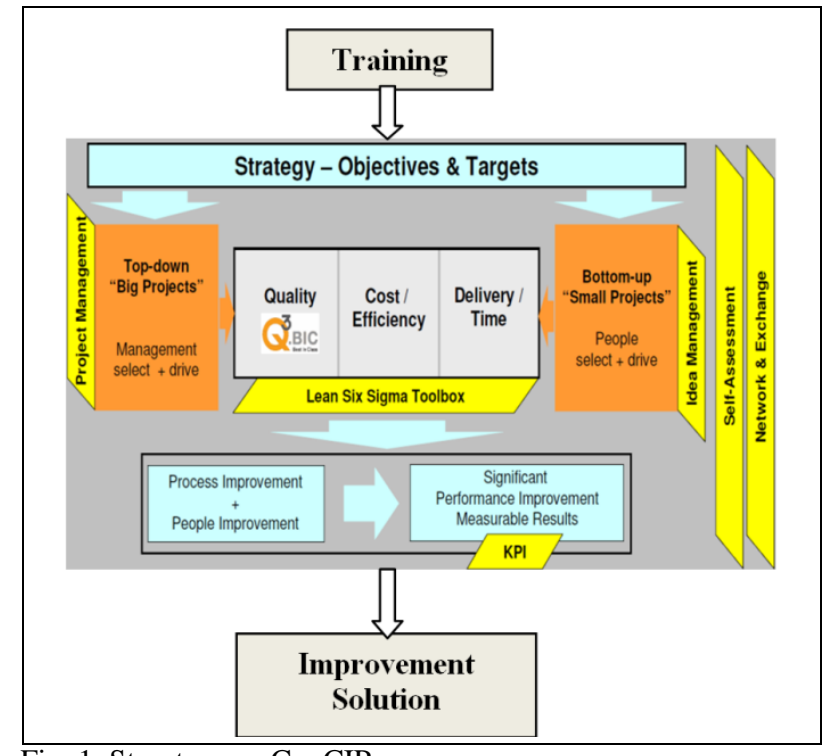

Fig. 1. Structure on ConCIP

Ensure improvement project are being carried through efficiently and deliver results by providing a proven procedure.

Levels: green belts, black belts, master black belts and intenal training approach being rolled out. Training by internal, local/regional trainers or, if no other chance, by approved external sources, selected tools (mostly from lean) for activities in the non-production-areas.

The goal of the define phase is to design the project based on customer requirements and present it in measurable parameters.

The target of the measure-phase is to describe the current situation on the basis of measurement variables. The measurement system's capability is tested and process capability is assessed. The aim if analyze-phase is to deremine quantities of process influences and elaborate a list of possible causes $\mathrm{X}$. the list of possible causes $\mathrm{X}$ shall limited to 3-7 important causes by the means of various testing methods. 
Solutions of problems are elaborated and implemented in the improve-phase.Is the target in the control phase to quarantee the $\mathrm{Y}$ process capability in the long term by controlling the important $\mathrm{X}$ and the sustainability of the implemented measures. The process owner takes over the responsibility for the safeguard of the project results. The project team is to be dissolved.

\section{APPLICATION EXAMPLE}

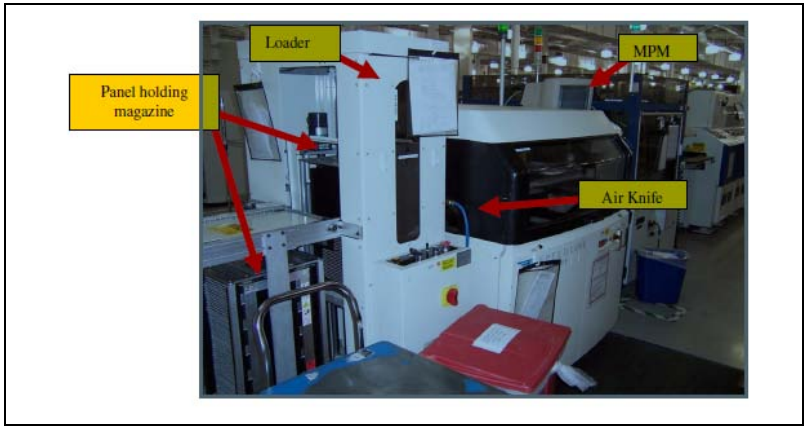

Fig. 2. Machine for assembling the basic board

Problem description is customer dissatisfaction due to PCM fault. Foreing material found under solder indicating that the event occurred before the MPM solder placement process.

The process steps begins with 50 panels in storage magazine and placed into the loade, places 1 panel onto the conveyor positioned next to the MPM solder placement machine. Problem solution, hardware/software implementation of an air knife assembly that would remove any foreign material on the panel surface before the MPM solder placement process. As the panel transmition the panel onto the conveyor next to the MPM solder placement machine, the air knife is activated and removes any foreign material on the panel surface.

\section{DEFINITION OF DEFECTS PER UNIT}

DPU is defined as number of errors that was detected at the inspection point per number of units that passed the inspection point. DPO is number of errors per opportunities and is an universal quality measurement that considers possible errors and had as definition number of errors that was detected at the inspection point $\mathrm{x}$ 1.000.000 per number of opportunities $\mathrm{x}$ units.

An example of Lean Six Sigma application:

A person goes to work

One person lives approximately 10 minutes driving time from his work. He attends Six Sigma training. He knows that in Six Sigma there is a lot related to figures. That is why during the last weeks he measured how many minutes the way takes.

Results (table. 1):

\begin{tabular}{|c|c|c|c|c|c|}
\hline \multicolumn{2}{|c|}{ Week 1 } & \multicolumn{2}{c|}{ Week 2 } & \multicolumn{2}{c|}{ Week 3 } \\
\hline Day : & Min : & Day : & Min : & Day : & Min : \\
1 & 10 & 1 & 10 & 1 & 10 \\
2 & 18 & 2 & 9 & 2 & 10 \\
3 & 16 & 3 & 16 & 3 & 9 \\
4 & 11 & 4 & 11 & 4 & 10 \\
5 & 10 & 5 & 10 & 5 & 11 \\
\hline
\end{tabular}

Tab. 1. Table with results for 3 week

What can we do with these data?To calculate the average for the days:

$$
\bar{X}=1 / 15 *(10+9+11+10+\ldots \ldots \ldots . .+9+10+11)=11 \mathrm{~min} .
$$

To calculate the average for a week:

$$
\bar{X}_{1}=1 / 5(10+9+11+10+10)=10 \mathrm{~min}
$$

$$
\begin{aligned}
& \bar{X}_{2}=1 / 5(10+18+16+11+10)=13 \mathrm{~min} \\
& \bar{X}_{3}=1 / 5(10+10+9+10+11)=10 \mathrm{~min}
\end{aligned}
$$

- $\quad \mathrm{X}$ is the average of a group of data

Differences between the data

Range $(R)=($ the highest value - the lowest value $)$

$\mathrm{R}=18-9=9$ min (the total range)

$\mathrm{R}=11-9=2$ min (range of the first week)

$\mathrm{R}=18-10=8 \mathrm{~min}$ (range of the second week)

$\mathrm{R}=11-9=2$ min (range of the third week)

Variance:

$$
S^{2}=\frac{1}{n-1} \sum_{i=1}^{n}\left(x_{i}-\bar{x}\right)^{2}
$$

$\mathrm{S}^{2}$ - is the variance of data group.

For 1 week:

$$
\begin{aligned}
& S_{1}^{2}=\frac{1}{5-1} \sum_{i=1}^{5}\left(x_{i}-10\right)^{2}=0,5 \\
& S_{2}{ }^{2}=\frac{1}{5-1} \sum_{i=1}^{5}\left(x_{i}-13\right)^{2}=14 \\
& S_{3}{ }^{2}=\frac{1}{5-1} \sum_{i=1}^{5}\left(x_{i}-10\right)^{2}=0,5
\end{aligned}
$$

For all 3 weeks is important:

$$
S^{2}=\frac{1}{n-1} \sum_{i=1}^{15}\left(x_{i}-11\right)^{2}=6,43 \mathrm{~min}
$$

\section{CONCLUSION}

The paper has shown is to show that the combination of Lean and Six Sigma can produce remarkable results and is the most powerful engine available today for sustained value creation. Case studies have been provided to illustrate how results are achieved.Some people have described Lean Six Sigma as "doing quality quickly", which may seem counterintuitive at first. Intuition tells us that faster we go, the more mistakes we make. If that were the case, trying to speed up a process would only result in lower quality. But Lean Six Sigma works not by speeding up the workers or the machines, but by reducing unneeded wait time between valueadd steps.

This reasarch it propuse to give us a image about to solution for improvement the times management and how I put togher two conception, lean and six sigma.

\section{ACKNOWLEDGEMENT}

This work was partially supported by the strategic grant POSDRU/88/1.5/S/50783, Project ID50783 (2009), co-financed by the European Social Fund - Investing in People, within the Sectoral Operational Programme Human Resources

\section{REFERENCES}

Greg Brue, Six Sigma for Small Business

Sung H. Park, Six Sigma for Quality and Productivity

Jeffrey K. Liker, 14 Management Principles from the World's Greatest Manufacturer

Michael L. George, Lean Six Sigma in Continental Automotive Grup Romania the Toyota Way 